\title{
Federated Digital Platforms: Value Chain Integration for Sustainable Infrastructure Planning and Delivery
}

\author{
Konrad Nübel ${ }^{1, *(\mathbb{D})}$, Michael Max Bühler ${ }^{2}(\mathbb{D})$ and Thorsten Jelinek $^{3}(\mathbb{D})$ \\ 1 Chair of Construction Process Management, Technical University Munich, 80333 Munich, Germany \\ 2 Faculty of Civil Engineering, Konstanz University of Applied Sciences, 78462 Konstanz, Germany; \\ mbuehler@htwg-konstanz.de \\ 3 Taihe Institute, 10787 Berlin, Germany; thorstenjelinek@taiheglobal.org \\ * Correspondence: konrad.nuebel@tum.de; Tel.: +49-89-2892-2411
}

check for updates

Citation: Nübel, K.; Bühler, M.M.; Jelinek, T. Federated Digital Platforms: Value Chain Integration for Sustainable Infrastructure Planning and Delivery. Sustainability 2021, 13, 8996. https://doi.org/ $10.3390 /$ su13168996

Academic Editor: Víctor Yepes

Received: 16 July 2021

Accepted: 3 August 2021

Published: 11 August 2021

Publisher's Note: MDPI stays neutral with regard to jurisdictional claims in published maps and institutional affiliations.

Copyright: (c) 2021 by the authors. Licensee MDPI, Basel, Switzerland. This article is an open access article distributed under the terms and conditions of the Creative Commons Attribution (CC BY) license (https:// creativecommons.org/licenses/by/ $4.0 /)$.

\begin{abstract}
Twenty-first century infrastructure needs to respond to changing demographics, becoming climate neutral, resilient, and economically affordable, while remaining a driver for development and shared prosperity. However, the infrastructure sector remains one of the least innovative and digitalized, plagued by delays, cost overruns, and benefit shortfalls. The authors assessed trends and barriers in the planning and delivery of infrastructure based on secondary research, qualitative interviews with internationally leading experts, and expert workshops. The analysis concludes that the root-cause of the industry's problems is the prevailing fragmentation of the infrastructure value chain and a lacking long-term vision for infrastructure. To help overcome these challenges, an integration of the value chain is needed. The authors propose that this could be achieved through a use-case-based, as well as vision and governance-driven creation of federated digital platforms applied to infrastructure projects and outline a concept. Digital platforms enable full-lifecycle participation and responsible governance guided by a shared infrastructure vision. This paper has contributed as policy recommendation to the Group of Twenty (G20) in 2021.
\end{abstract}

Keywords: sustainable infrastructure; federated digital platform; governance; design; protocols; implementation; value chain; digitalization

\section{Introduction}

\subsection{The Context of the Sutainable Infrastructure Challenge}

Sustainable infrastructure development and delivery is a core task of societies [1]. It is the basis of increasing social and economic connectivity. Sustainable infrastructure can be understood as the manifestation of a collaborative and creative process of improving social and economic development. Infrastructure development and delivery are an essential part of this process. Various perspectives and goals, such as human-centered design, economic efficiency, and sustainability, must be considered and counterbalanced in a holistic manner. On the one hand, the development process is a solution-oriented dialogic process of counterbalancing trade-offs. On the other, it is a process of fitting the solutions in a technical, social, and cultural context expressed through regulations, standards, and technological systems, as well as implicit social and cultural norms. This process is highly complex and marked by uncertainty where many stakeholders must be coordinated to reach a shared sustainable goal [2].

In contrast to factor and efficiency-driven economies [3-5], for instance those in Asia, no significant progress in infrastructure development can be observed in recent decades in most Western countries [6]. Moreover, investments in infrastructure are declining, including the investments provided by the World Bank that have strongly receded in the past [7]. Although it is clear that infrastructure development is central to sustainable, economic, and social development, many infrastructure projects are blocked by civil protest, suffer substantial benefit shortfalls, are severely delayed, and experience major 
cost overruns [8-11]. Public legitimacy, political will, and the know-how to change this situation are lacking [12]. Promising infrastructure initiatives have been initiated by G20 member states ("The G20", abbreviation for Group of Twenty, is the international forum that brings together the world's major economies. Its members account for more than $80 \%$ of world GDP, $75 \%$ of global trade and $60 \%$ of the population of the planet. The forum has met every year since 1999 and includes, since 2008, a yearly Summit, with the participation of the respective Heads of State and Government, see: [13]), the OECD, the World Economic Forum and by other initiatives on national and international levels. However, often such recommendations are not adopted and implemented into national planning and delivery processes [14-18].

Implementation visions and bankable sustainable infrastructure pipelines that bridge political cycles and are not prone to political risk are inadequate or lacking $[19,20]$. On the contrary, the lack of sustainable measures, flow-efficiency, sequential planning, discipline silos still determine common infrastructure practices.

\subsection{Structure of the Article and Approach to Solution}

The paper first discusses the problems arising in the development and delivery of sustainable infrastructure and concludes that those problems need holistic solution frameworks (see also Figure 1) and a holistic strategy for the future planning and implementation of infrastructure projects. The term "holistic" is understood as the integration of four different perspectives on infrastructure development [21], which are:

- The individual internal perspective (human-centered), i.e., the needs-based perspective of direct and indirect users of infrastructure objects (subway, water supply, etc.);

- The individual external perspective (technology-enabled), i.e., the required competencies of all persons involved in the planning and implementation process;

- The collective internal perspective (culture-embracing), i.e., the consideration of cultural aspects in infrastructure development;

- The collective external perspective (system-thinking), i.e., the adaptation of planning to all legal and technical regulations.
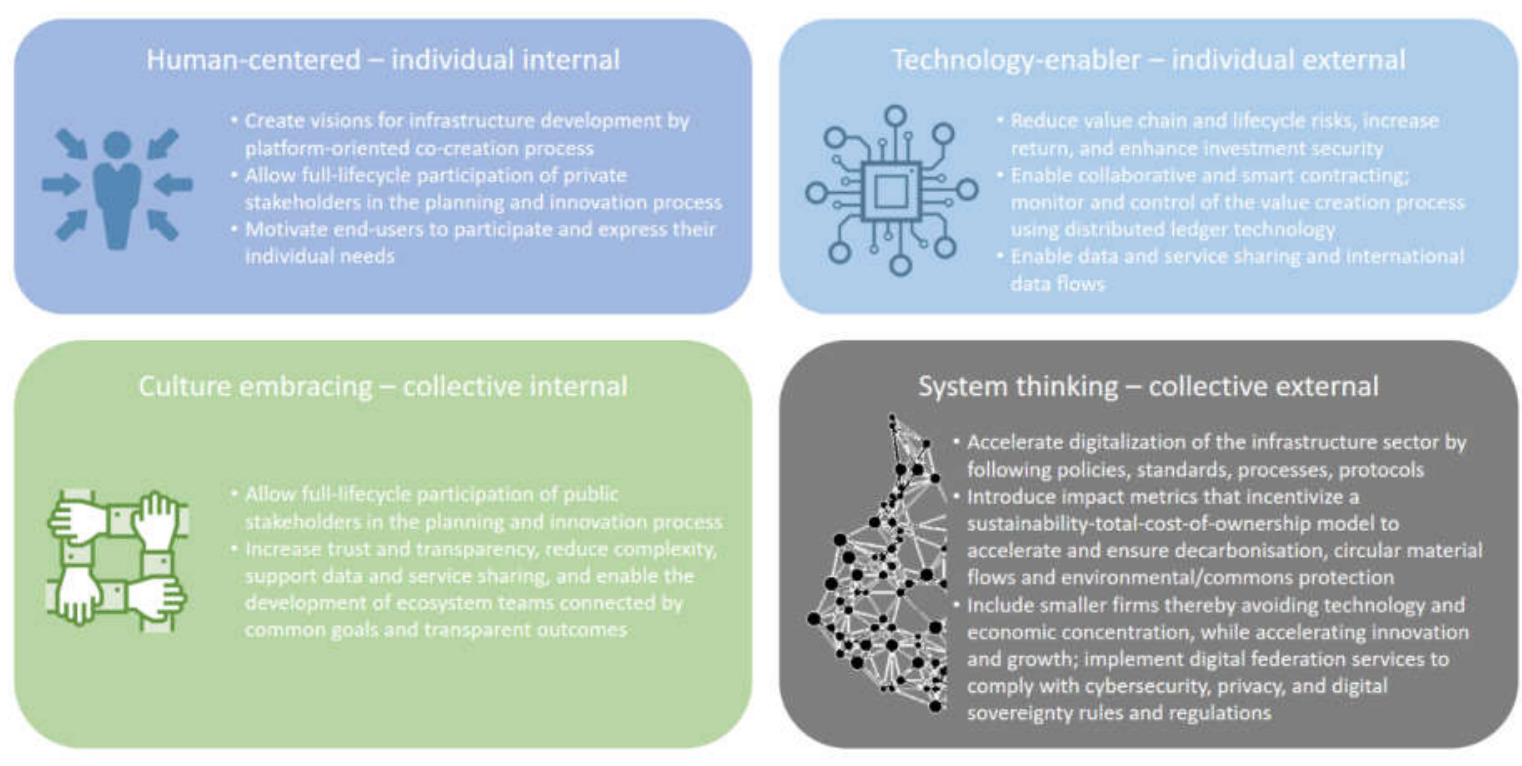

Figure 1. Holistic perspectives on infrastructure development.

Based on such holistic framework, the authors of this article propose to drive infrastructure development and delivery towards a much more integrated multi-stakeholder platform-oriented approach by using disruptive technologies. Such approach could enable solution-oriented, dialogical, and regulative processes. 


\subsection{Policy and Governance of Infrastructure Development and Delivery}

As a global challenge, infrastructure is discussed on a multilateral level. It is a priority especially for the Group of 20 (G20) given the forum's broad representation of economic activity (its member states represent circa $90 \%$ of global GDP and $80 \%$ of global trade), its considerable influence on international policy coordination and framework design, as well as lose diplomatic linkages between the large economic blocs. Past discussions between G20 leaders have led to the establishment of the Global Infrastructure Hub, the Global Infrastructure Connectivity Alliance, G20 Principles for Quality Infrastructure Investment, and the G20 InfraTech agenda [22-24]. However, the authors of this paper believe that the uptake and implementation of recommendations by G20 member states can still be improved. The G20's focus on investment finance needs to be complemented by an engineering design and delivery focus for sustainable infrastructure, as well as by an inclusive digitalization focus addressing the fragmentation of the industry.

This paper has contributed as policy brief to the G20 gathering in Italy in 2021 and, respectively, to the Think 20 (T20) task force 7 "Infrastructure Investment and Financing" (see Appendix A). The T20 is the official engagement group of the G20, bringing together leading think tanks and research centers worldwide. The T20 serves as the G20's policy incubator and aims at providing research-based policy recommendations to the G20 leaders.

\section{Methodical Approach}

The authors of this article carried out more than 30 semi-structured online interviews with infrastructure experts (see list of contributors listed below as "additional contributors"), two online conferences in Germany (one on a national level and one on an international level) with more than 100 participants, as well as contributed to numerous G20/T20 Task Force meetings on infrastructure investment and financing. Both infrastructure workshops encouraged interactive discussions including break-out group discussions. The methodology of qualitative interviews in combination with problem-centered questions is an effective approach for investigating the implicit dimension of expert knowledge and tapping into the interlocutor's professionals, as well personal experience in the search of explanation [25].

Prior to the interviews, the authors consulted existing literature to extract the most effective approaches to prevailing infrastructure challenges by focusing on the "waterfall model," which still dominates infrastructure planning and delivery [11,26-32]. The results are discussed in the following.

\section{Outcome of the Expert Interviews, Workshops, and Literature Assessment}

There is an industry-wide consensus that driving best practices in infrastructure planning and delivery includes:

- A well-articulated vision for infrastructure that enables a systematic development of a robust pipeline of bankable projects and long-term plans with robust business cases;

- Strong project governance arrangements to enable strong project delivery including a more agile set of regulations to reflect optimal practice embracing new infrastructure technologies;

- The careful management of societal and environmental impacts to support project delivery. An early and thorough multi-stakeholder participation minimizes risks and maximizes positive overall outcome. Risk transfer needs to be carried out appropriately to maintain value for money;

- A procurement model chosen on the basis of project specifics and rigorously following established published guidelines.

However, this very condensed evaluation is not surprising. The common infrastructure problems are well known globally and are frequently analyzed and evaluated. However, in many cases the question arises as to why governments and institutions do not simply implement leading practices and state-of-practice recommendations. The authors 
of this article and the key contributors to the article listed below have studied this question in depth and have developed the following hypothesis:

As the process of infrastructure development and delivery is very complex, the best practice approach is to decompose the overall task into smaller components which are understandable and manageable. This approach is a basic principle in our economy based on division of labor. The process of infrastructure development and delivery in most countries is, therefore, a stepwise phase process, where the next phase begins as soon as the preceding phase is closed [33]. The level of granularity of planning increases with each phase until it is brought to a constructible planning state. Such linear consecutive processes are called "waterfall model" [34].

Each phase is executed independently and has its particular composition of stakeholders. Often, project leadership also changes across different phases. The process is so segregated that a common understanding of the entire process does not exist among the majority of relevant stakeholders, and the process itself regularly loses sight of the desired outcomes. As a result, problems in the process are usually addressed in a specific phase or even within a sub-phase, while the entire process model is hardly questioned. This approach is seen as a common way of avoiding change.

Consequently, such complex multi-stakeholder processes tend to lead to a multidimensional principal-agent dilemma in which asymmetric information policies predominantly increases local efficiencies in the functional silos of the project. However, the optimization of the benefits of the overall system, or even more, the interests, needs, and requirements of the infrastructure asset users move entirely out of sight.

To understand the root causes, problems must first be addressed and related to the specific phase or component of infrastructure development and delivery. As mentioned earlier, the problems existing at this granular level are well known. This approach is necessary, but not sufficient; it is not sufficient since the overall problem of asymmetric information cannot be solved at the specific level of granularity. Moreover, the problem of slow planning processes or administrative hurdles will not be solved simply by accelerating the planning processes nor merely by reducing administrative hurdles. Instead, a system change is needed that allows for a holistic solution that can simultaneously address the four perspectives explained in Section 1.2.

In other industry sectors, we see that value creation evolves through trusted networks of collaboration, so-called value networks [35]. The underlying multistakeholder and multidisciplinary ecosystems increasingly become the backbone of our digitalized world, mobilizing specialized actors that share values, governance principles and common goals. Value networks are interactive, integrative and agile, and focus on people's needs. In infrastructure development and delivery, however, such value chain integration is lacking [8] and very important to achieve usability and sustainable goals.

We can conclude that the global infrastructure gap [36] and the need to develop sustainable infrastructure cannot be eliminated by taking only the financial aspects into account; the whole value chain of development and delivery has to be transformed into an integrated system, a value network, focused on end user needs but also on social requirements, as well as a much broader approach to value creation. The root cause is the existing fragmentation and lack of cooperation within the infrastructure value chain. Sequential (waterfall) planning and resource-efficiency (focusing on silos) are still common practice, compared to the necessary flow-efficiency and agility (across the value network), preventing a more impactful realization of broader goals.

Therefore, a holistic approach (Figure 1) of development and delivery of sustainable infrastructure is needed to integrate the value chain in this important economic sector. By focusing on the traditional "waterfall model," such integration cannot be achieved.

\section{Proposal of Federated Digital Platform for Sustainable Infrastructure}

Traditionally, value is created within the boundaries of an enterprise or a value chain. In contrast, digital platforms challenge incumbents by changing how a value network 
consumes and provides products and services. Digital platforms, which utilize an ecosystem of autonomous agents to co-create value, have the potential to overcome the existing fragmentation of the infrastructure value chain [37]. The sharing and reusing of data and pioneering technologies-such as cloud and edge computing, artificial intelligence, digital twins, IoT and smart sensors, 5/5.5 G, and distributed ledgers-can help to integrate the value chain, and thereby enhance infrastructure productivity, efficiency, and affordability. Such platform-driven integration can also spur innovation through ecosystem participation and accelerate the achievement of the broader objectives of decarbonisation, resilience, and human-centered infrastructure [38].

The digital transformation of the infrastructure sector provides the opportunity to increase investment efficiency and sustainability. Digitalization could positively impact the localization and realization of the United Nations' Sustainable Development Goals (SDGs) [39]. Moreover, digital transformation can enable transparent criteria for ESG (environmental, social, and corporate governance) investment, which will be a driving force in the future. The advantages and progress of state-of-the-art cyber-physical systems in infrastructure, including advancements in sustainability and decarbonization, is well documented [40]. However, despite significant progress-e.g., by applying building information models (BIM), a decision-making instrument that already leverages various digitalization tools and applications-major challenges remain for the actors involved in infrastructure projects [41]. Therefore, the authors believe that digital platforms have the potential to function as a transformative marketplace between the public and private sector, in particular for smaller businesses.

This article proposes digital platforms for infrastructure as mobilization and learning platforms to address and overcome the limitations of the existing platform economy [42-45]. Mobilization platforms bring existing expertise together to create shared outcomes. They enable and make multistakeholder co-creation processes more effective throughout the entire infrastructure lifecycle. Mobilization is needed not only to integrate the various silos of infrastructure delivery into a single process and project, but also to create entire infrastructure ecosystems that are open to outside parties who can build complementary products and services. Mobilization platforms can and should evolve into learning platforms. Learning platforms provide the level of agility, resilience, and antifragility that is needed for continuous improvement, innovation and adaptation to a rapidly changing environment [46,47]. Modeling digital platforms as learning platforms will help to coordinate and accelerate the digitalization of infrastructure and the transformation of infrastructure production and delivery methods [48]. Utilizing the concept of mobilization and learning platform as an underlying value and structure of digital platforms, the potential upside of infrastructure digitalization can be tremendous.

For the classification a holistic model, [21] is used as already explained in Section 1.2. Importantly, digital platforms can enable the transformation towards Sustainable Infrastructure 4.0, but they will not intrinsically realize those benefits or resolve the challenges associated with traditional infrastructure, see Figure 1. Considering their dual-use and disruptive character, advanced technologies can even be part of or worsen humanity's challenges $[49,50]$. This is why governments introduce new laws and regulations that aim to make advanced technologies and digitalization secure and safe while serving the needs of society. Hence, this article is premised on the assumption that governance and, therefore, some degree of coordination and regulation are crucial for a successful transition toward Sustainable Infrastructure 4.0.

\subsection{Mobilization and Learning Platforms for Infrastructure}

The path of working towards the creation of a digital platform for the design, construction and operations of built environment assets creates a tremendous opportunity. The development process could not only improve the symmetry of knowledge amongst the stakeholders, but also lead to the converges of existing systems within the value chain into a mobilization and learning platform. Platform creators and key platform participants 
should take into consideration five dimensions of this iterative process of "systems convergence and platform emergence" to harness the benefits of such transformation process, as illustrated in Figure 2: governance, design, protocols, implementation, and use cases. Each dimension is presented in detail in the subsections below.

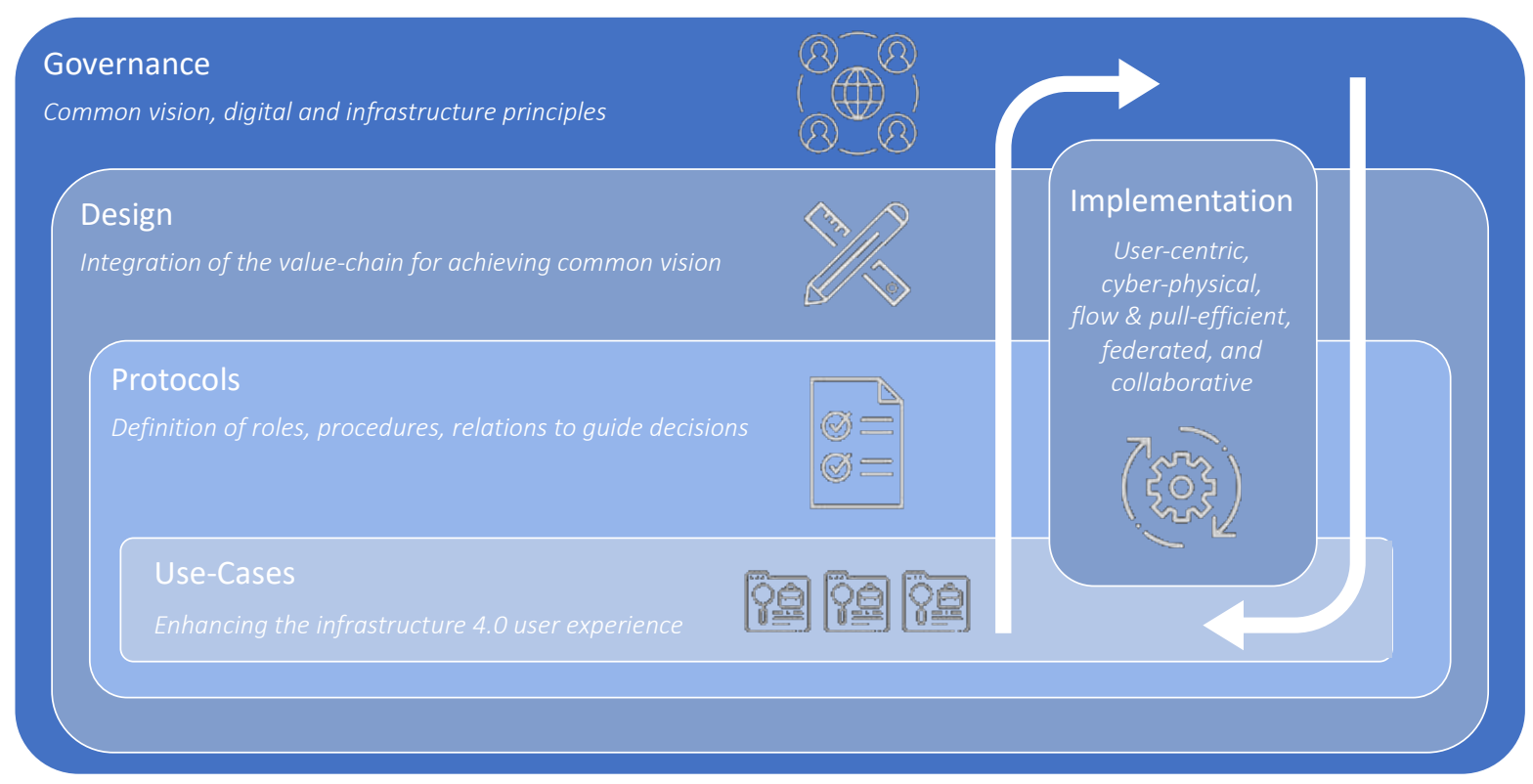

Figure 2. Five dimensions of implementing a mobilization and learning platform.

\subsection{Analysis of the Five Dimensions}

\subsubsection{Governance}

As indicated above, technology itself will not solve the limitations of traditional infrastructure. On the contrary, the OECD [51] identifies infrastructure mainly as a governance challenge. However, a digital platform does not simply operate without governance but already emulates a governance structure that determines rules, as well as facilitates and regulates the interaction of participants and the sharing of data and data services [42]. This is why governance is the most crucial dimension of planning, developing, and operating a digital platform for infrastructure. If governance can be construed as the possibility for collaboration directed by common principles, as well as a space that limits human autonomy, a platform provides the opportunity to restrict unwanted behavior and enable or incentivize desirable behavior for the purpose of reaching common goals [52].

The OECD [51] lists a set of infrastructure governance challenges that need to be addressed to avoid the existing infrastructure governance gap [53] merely being replicated through a poorly designed digital governance structure. According to the OECD, a sound infrastructure governance framework requires: (1) a shared strategic vision for infrastructure service needs; (2) a strategy for mitigating integrity risks; (3) a common method of infrastructure delivery that balances political, societal, economic, and strategic interests; (4) a sound regulatory design and approach; (5) a consultation process to meet the demands of the general public; (6) policy coordination across the different levels of government; (7) a long-term infrastructure strategy that ensures both affordability and assets performance; (8) data for fact-based decision-making; and (9) infrastructure systems that are resilient and adapt to new circumstances. In addition, infrastructure governance should also incentivize and reinforce environmental and social sustainability standards.

For the purpose of developing a digital platform, those overarching governance requirements, which are mainly targeted at governments, need to be translated into more specific rules across three different domains of hard and soft governance, including (1) the digital infrastructure and data governance domain, (2) the infrastructure project life cycle 
domain, and the (3) legal, regulatory, and industrial standards domain. From a platform design perspective, digital federation services [54] function as the specific technological and digital representation of those different governance requirements and manifest as digital platform protocols [55]. The term federation emphasizes the governance aspect of mobilization and learning platforms. Based on the design and specification of those protocols, a platform can, therefore, enforce a desired degree of value chain integration through information transparency and the possibility of collaboration based on shared data spaces and data services. Platform governance can, therefore, represent the aspects of integrated project delivery [56].

Importantly for the development and operations of such a federated digital platform, the article recommends mapping the core regulations, standards, and processes of infrastructure delivery, as well as the regulatory requirements concerning cybersecurity, privacy, and data sovereignty (see Figure 3). Both sets of federation services, one for infrastructure, the other for the digital infrastructure and data ecosystem, constitute the core governance framework of an emerging digital platform for infrastructure delivery. Although cloud providers and hyperscalers will naturally focus on federation services regarding the trustworthiness of the digital infrastructure and data ecosystem, the federation services concerning the virtualization of the development, design, construction, and operations processes for the built environment assets still need to be developed.

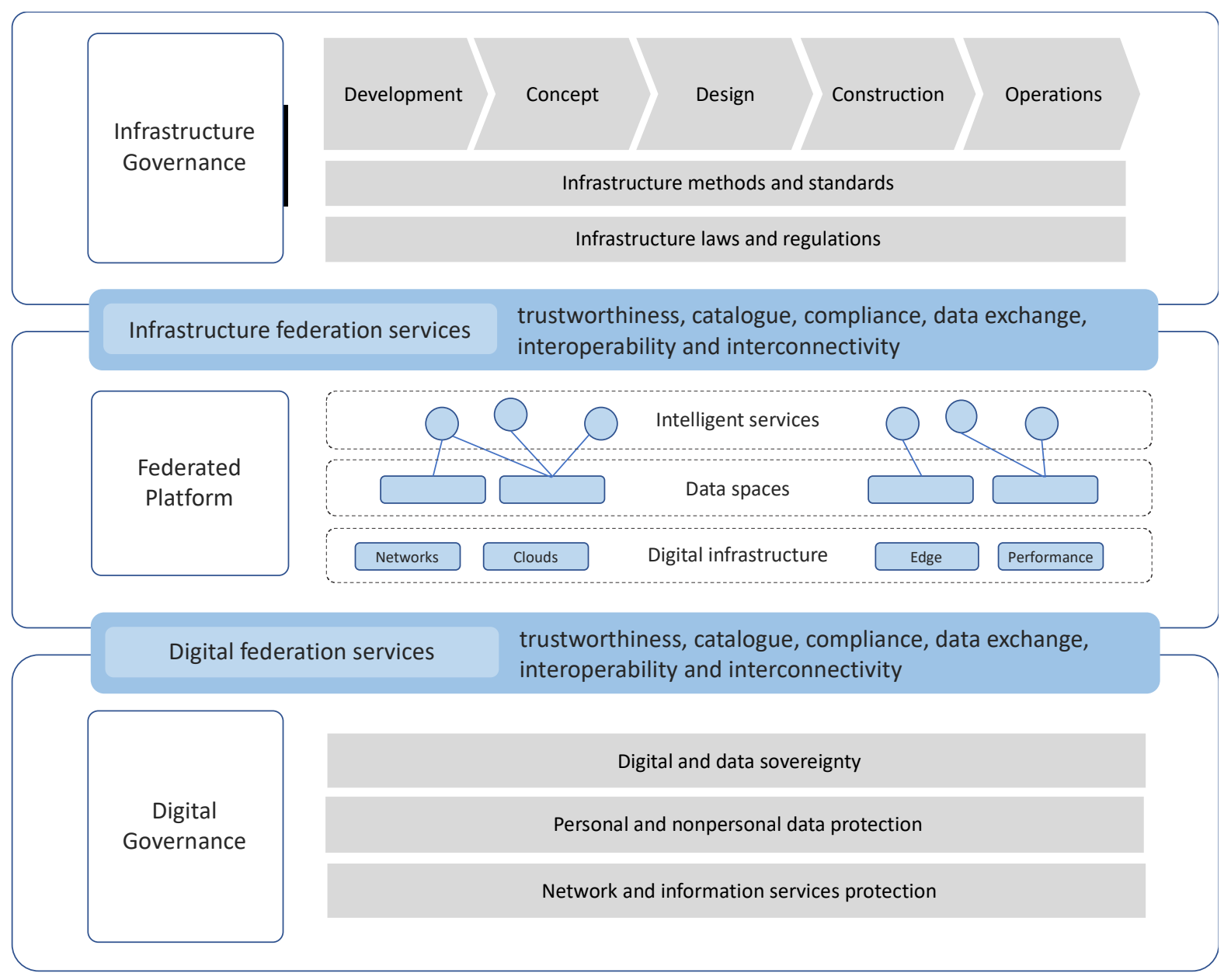

Figure 3. Governance structure of the federated digital platform for infrastructure.

As presented in the following, such a governance structure is not realized through a traditional top-down systems integration approach. On the contrary, this federated digital platform is realized in a flexible, bottom-up approach by focusing on scalable and 
marketable use cases that eventually become part of an infrastructure ecosystem. The concept of federation suggests that data can be securely shared in a distributed manner in order to establish data alliances, but without compromising ownership.

The risks associated with technological dependency on global hyperscalers are among those that will be addressed by federated platforms (e.g., the US's NIST Cloud Federation Reference Architecture and the EU's Gaia-X Federation Services), and the implementation of these platforms will affect all dependent technological areas including sustainable infrastructure. The following objectives regarding digital sovereignty will enable novel business models and incentivize inclusive development by fostering an equitable platform ecosystem for infrastructure:

1. Avoid "lock-in" to a particular technology, with resulting technological and commercial dependency on the provider;

2. Reduce the risk of services being modified or terminated in an uncoordinated manner by the provider;

3. Share selected data and digital services to different ecosystems, while ensuring ownership, data, and privacy protection;

4. Gain access to open and trusted data spaces to maintain control over the development of new digital services within an interoperable and trustworthy digital and data infrastructure.

As presented in the following, such a governance structure is not realized through a traditional top-down systems integration approach or lengthy business process reengineering. On the contrary, this comprehensive platform is realized in a flexible, bottom-up approach by focusing on scalable and marketable use cases that eventually become part of an infrastructure ecosystem.

\subsubsection{Design}

The design of an infrastructure platform starts with developing the governance framework outlined above by taking into consideration hard and soft governance requirements. Hard governance relates to existing laws and regulations that tend to determine design choices. Soft governance requirements mainly relate to standards, processes, and legacy systems. Their manifestation within the new platform is an iterative process evolving over time. Hence, to manage the platform development in an agile way, the platform design should be centered around the development of use cases, which also leaves space for exploration and experimentation.

A platform tends to grow along its most effective use cases first and then gets shaped by the ecosystem that surrounds it. Therefore, prioritized use cases have to be identified, developed, and implemented. Use cases should be or must have the potential to become business cases, since only competitive and marketable concepts will foster their adaptation and scalability. The platform develops with the development and adaptation of its best business cases [57]. The scalability of use cases is achieved by structuring, standardizing, modularizing, and connecting with existing solutions. Promising business models could already be created using existing data and employing exponential technologies. Design decisions have been made concerning the degree of intelligent automation, data sharing, and collaboration across organizational boundaries. Such a design approach allows for relocating innovation to an emerging ecosystem and a huge network of outside firms. However, use cases must be identifiable within the infrastructure process and life cycle.

Furthermore, to overcome the value chain fragmentation and lack of collaboration within the infrastructure industry on public-sector projects, a multi-stakeholder, as well as a multi-phase perspective must be taken and an integrated project team, including the project owner, must be formed [58]. The learnings from the UK's National Digital Twin initiative [59], two decades of building information modeling [60] and experience of other industry sectors should be considered, including procurement of hospitals and highways using the integrated project delivery ("IPD") approach [61]. 
Although the platform's digital architecture should be based on the principles of security and privacy by design/default to ensure trustworthiness, the infrastructure use case architecture should be based on the principles of collaboration and flow-efficiency by design. The collaborative framework must include the early involvement of all stakeholders and needs to be outcomes-based. It must measure metrics of operational results to validate success or failure of outcomes, including traditional metrics, such as output performance in terms of cost, time, scope, and quality, but also other indicators, such as resilience, environmental standards, and social impact. The collaboration framework needs to include an effective dispute resolution mechanism as well as pain, gain, and risk sharing [62].

Although the focus of this policy brief is on public infrastructure, including publicprivate partnerships, this paper considers any infrastructure as being part of the commons (cf. [63]). The benefits of infrastructure investments could be more evenly distributed by closing the digital divide [64] and by applying, for instance, more inclusive COVID-19 recovery policies [65] enabled through open public consultation and participation processes in the early stage of infrastructure development [66]. Such a premise fundamentally influences the design of the platform. This is not to say that market dynamics are neglected. On the contrary, the platform design is premised on the profit ideal. Social and environmental sustainability standards no longer stand in opposition to market and profit considerations, yet conflicting goals need to be addressed. Thus, the core design principle should remain premised on the triple bottom line: people, planet, and prosperity [67]. Value creation has to be incentivized and should be derived from the shared infrastructure vision and governance principles.

\subsubsection{Protocols}

Protocols, which are agreed-upon or accepted sets of rules or standards for procedures, constitute a more granular level of platform design. Defining platform protocols helps to translate governance and design requirements into concrete procedures and source code [68]. They represent the specific roles of platform participants and their tasks, relations, and decisions associated within each domain and between the domains of governance. They guide decisions towards achieving shared values and objectives. Protocols function as a common language for stakeholders to develop the platform without the need to become too technical. A low- and no-code environment increase the adaptability of the platform and the integration of use cases [69].

As indicated in Figure 2, a set of protocols constitutes the federative services that enable trusted collaboration and data sharing across an ecosystem. Their definition allows for mirroring, optimizing, and streamlining infrastructure processes alongside the value chain, in relation to virtual and physical assets, and facilitating a seamless information exchange between stakeholders. Protocols can make pain points related to non-synchronized delivery processes or low-quality problems transparent, and help to monitor the development and delivery process of infrastructure projects [70].

Protocol metrics should be implemented to track the realization of common objectives. Legitimate protocols cannot be developed without stating the vision and objectives, as already outlined by the governance and design frameworks. In contrast, existing metrics can be realigned with the broader goals and strategy to make them meaningful. In essence, protocols directly address the governance gap and the myriad of challenges associated with traditional infrastructure delivery. However, protocols are never final but need to adapt to a constantly changing environment and increasing complexity [71].

\subsubsection{Implementation}

To respond to an increasingly complex and changing environment, which is marked by constant crises, requires an effective combination and application of implementation values and methods that support agility, resilience, and anti-fragility. Agility is a form of adhocracy and emphasizes flows and iterations. Resilience promotes self-organization and robustness through rapid adaptation, while antifragility suggests that improvement 
occurs even in the face of shocks $[47,72]$. Such project and work flexibility are required to manage digital technologies that are themselves disruptive. Today's dynamic development is supposed to intensify in the future, as the world is further changing towards an era of ubiquitous digitalization, heightened cyber-physical risks, and structural instabilities [73].

Although those methods are applied within the ICT industry, they rarely find application within the infrastructure and public sector. Thus, setting up a dynamic governance structure and developing a digital platform for use-case-based infrastructure development can create tension between technology, infrastructure, and public-sector participants. However, the infrastructure industry has developed its own set of innovative planning and delivery methods that should be considered and combined with those of the ICT industry.

Accordingly, those infrastructure methods are user-centric and flow- and pull-efficient, emphasize value generation, seek to reduce waste, and pursue perfection. In particular, lean construction requires the adaptation of lean principles originating from the Toyota production system ("TPS") to the construction sector. Lean thinking is the antidote to waste [74]. Target value delivery ("TVD") is a management practice that drives the design and construction to deliver customer value within project constraints [75]. The last planner system ("LPS") is a collaborative production management system [76]. Integrated project delivery ("IPD") is a construction project delivery method that seeks efficiency and involvement of all participants (people, systems, business structures, and practices) through all phases of design, fabrication, and construction [61]. Promoting the digital platform to the infrastructure sector is an opportunity for those methods to become the new modus operandi and help to realize the broader goals [48].

\subsubsection{Use Cases}

Use cases are at the center of the transformation towards a future era of infrastructure planning and delivery that is cyber-physical, user-centric, flow- and pull-efficient, and carbon-neutral. Infrastructure 4.0 also suggests the emergence of new business models and incentives for innovation and inclusive development [77]. During this transition, use cases should increasingly represent a dynamic cyber-physical world that functions as a domain of smart and automated conception/development, design/planning, construction/production, as well as operation, maintenance, and re-use (see Figure 4), such as:

- Organizing digital public consultation processes;

- Supporting a digital permitting process, e.g., for building permits;

- Enhancing urban planning considering climate resilience functions;

- Enabling generative, parametric, and collaborative design;

- Provision of unstructured data mining tools to support the infrastructure planning and delivery process including real-time work-site monitoring and management decision-making;

- Ensuring seamless flow of information during project development and planning phase;

- Transparent project delivery, e.g., project controlling, including risk monitoring and ESG controlling functions;

- New technologies for commercial processes;

- Provision of "Design-Construct-O\&M (Operate and maintain)"-as-a-Service.

Figure 4 also highlights the to-be-developed and operational digital federation services that enable secure, interoperable, decentralized, and sovereign data exchanges. Federation services can be offered by a trusted third party, and data sovereignty suggests that data can be shared for the development of digital services (see Figure 5) but without losing ownership [78]. The development of data alliances is crucial for data providers and consumers (like municipals) that lack big data, which yet is necessary to train machine learning and neural network-based algorithms. Based on the architecture provided by the International Data Spaces Association [79], Figure 6 further illustrates how a federated platform can enable digital assets and service offerings to be exchanged by its core platform participants, including data owners, data providers, consumers, and end-users. 

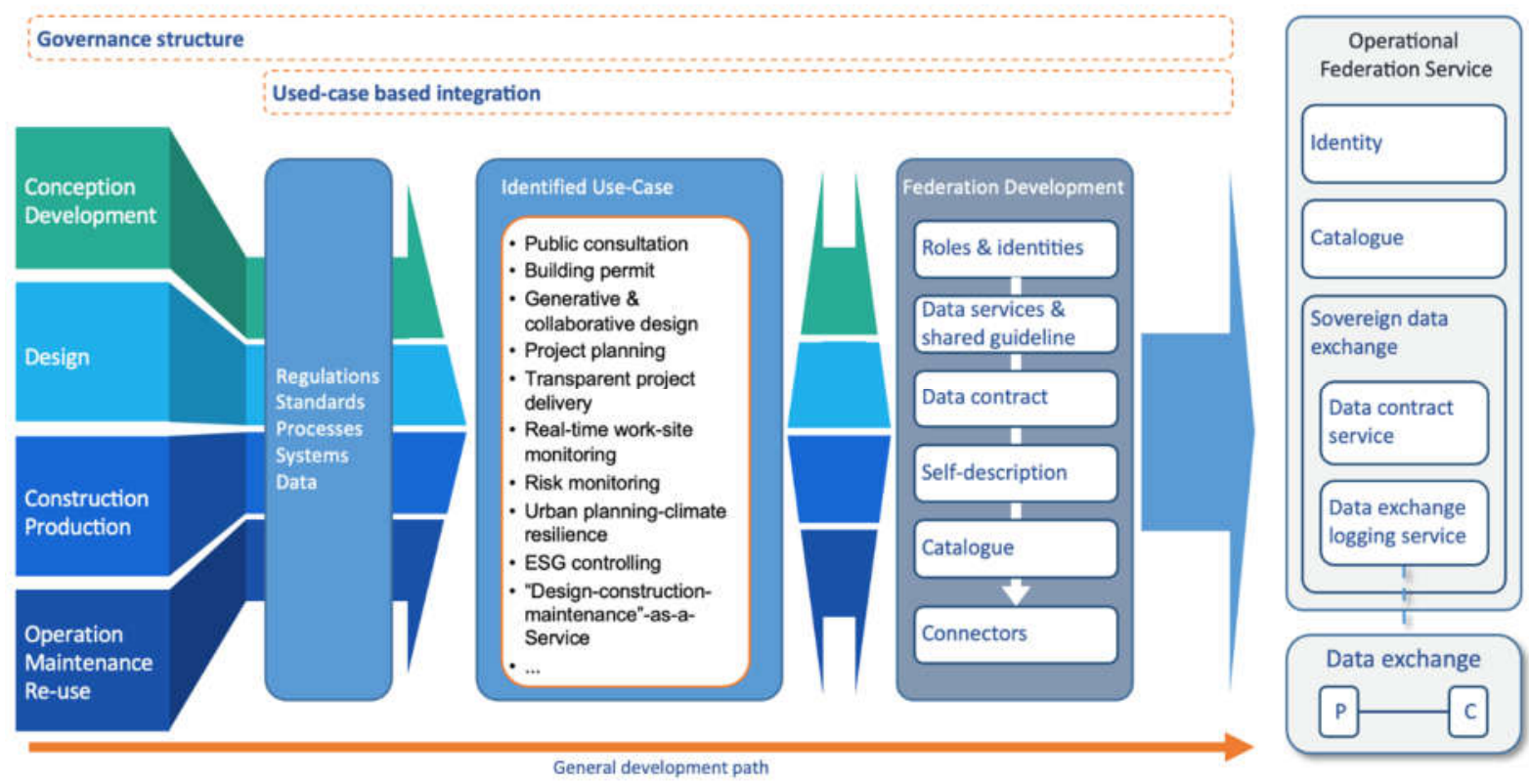

Figure 4. Typical use case integration along the infrastructure lifecycle.

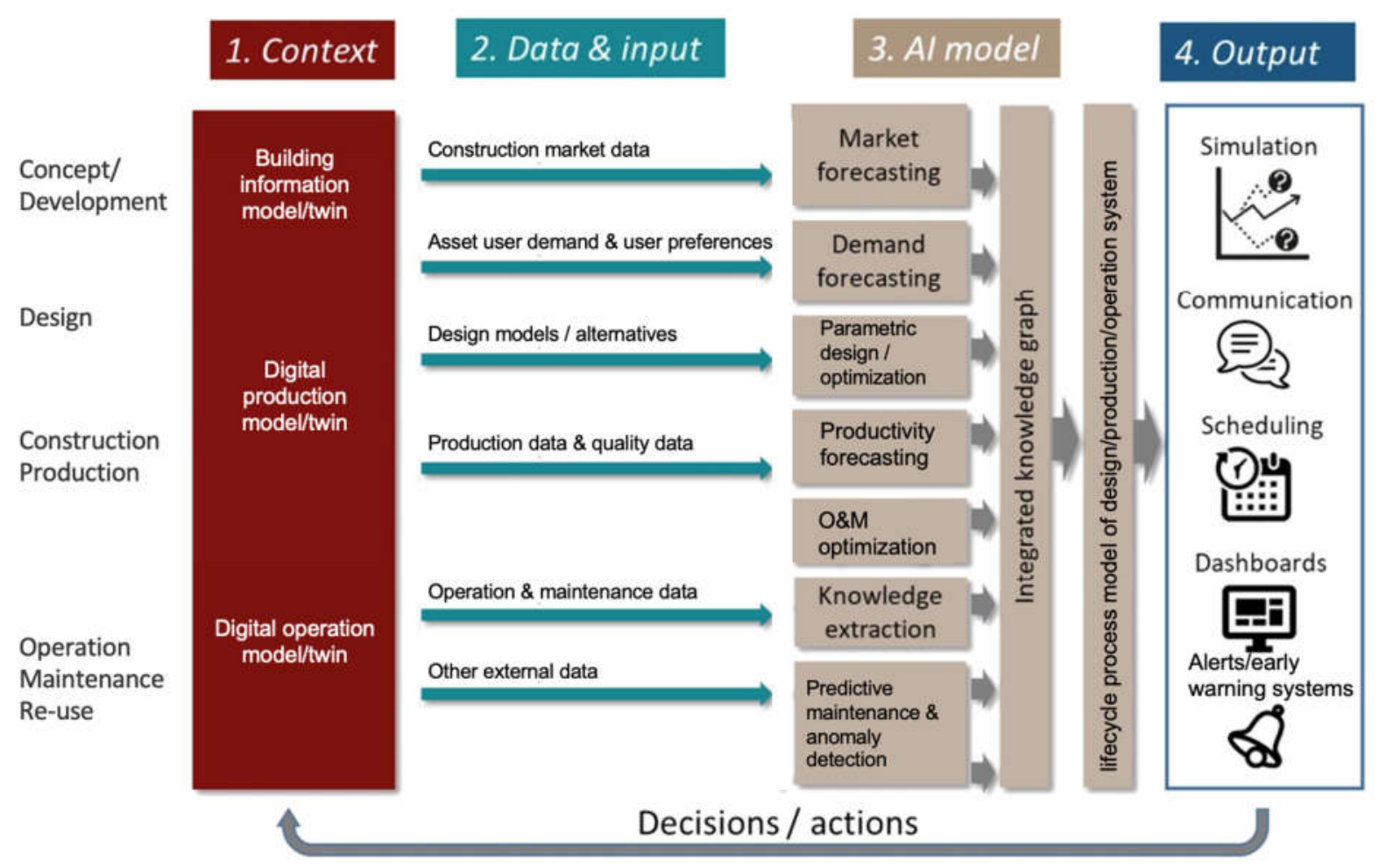

Figure 5. Applying digital twins throughout the infrastructure lifecycle (from building information model during design phase, digital production model during construction phase as digital operation model during O\&M phase) to process input data by means of artificial intelligence algorithms. Adopted from OECD Framework for Classifying AI Systems [80]. 


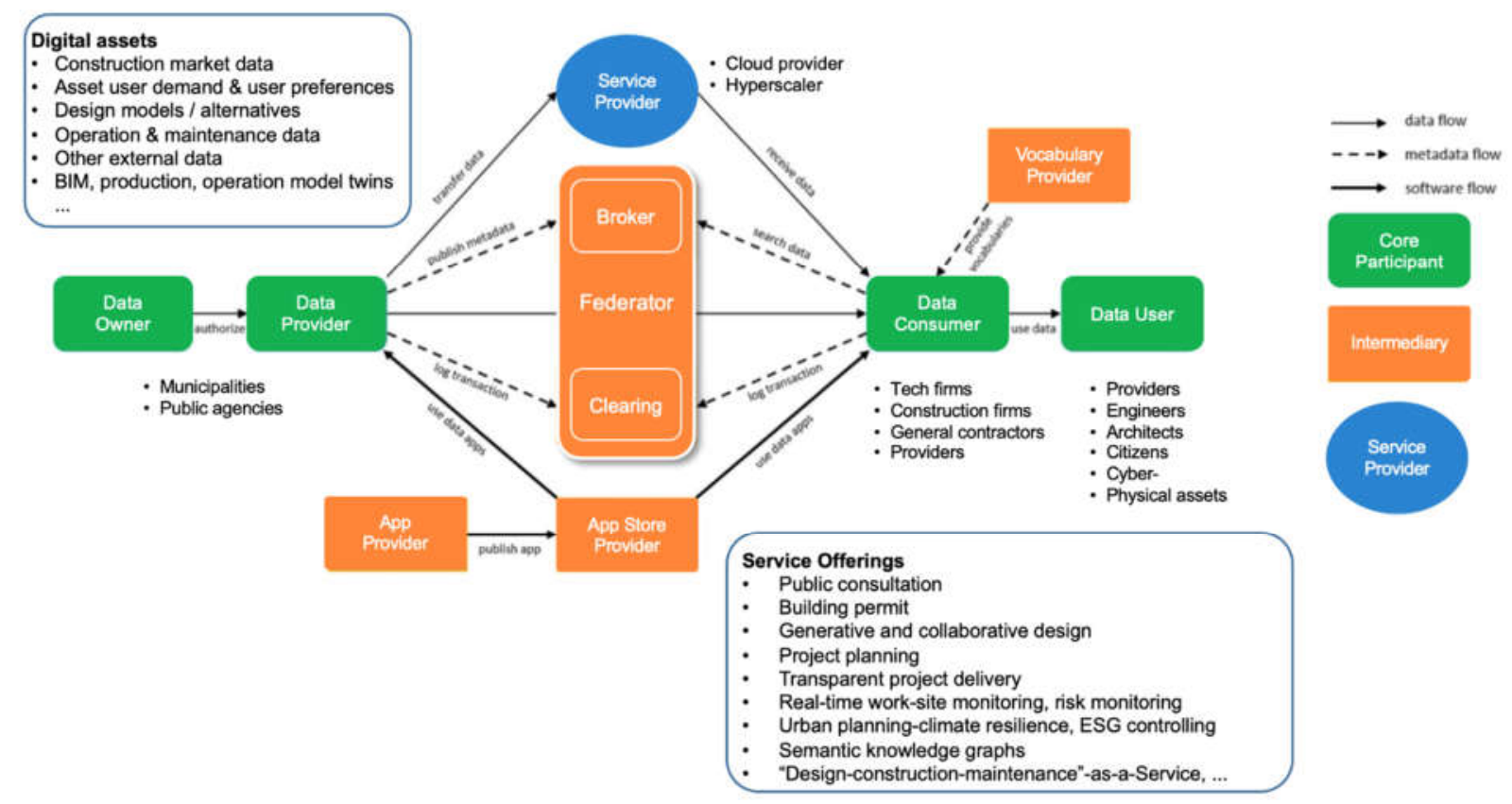

Figure 6. Digital assets, service offerings, and roles enabled by federated digital platforms (adopted from IDSA Reference Architecture Model [79]).

The development of use cases can start with individual applications and existing data. In the course of the platform implementation, a growing number of use cases increasingly constitutes as an ecosystem of trusted and open data spaces with links to other industries and regions. However, it is important that use cases are embedded from the outset within the digital and infrastructure governance and process frameworks in order to set the basis for overcoming the existing fragmentation of the value chain.

For governments to kick-start the development of mobilization and learning platforms, an inventory of micro and macro use cases should be identified, compiled, and prioritized using examples from the industry (e.g., interoperability standards for BIM data exchange), national government initiatives (e.g., the UK's Infrastructure Client Group's Project 13), G20 initiatives (e.g., InfraTech stock take of use cases), and the latest supra-governmental initiatives (e.g., Gaia-X federated digital platform), as well as examples of digital mobilization and learning platforms from other sectors, which will provide transferable knowledge. The promotion of use cases and the development of platforms can be accelerated through government funding and market mechanisms. Existing cloud platform systems and hyperscalers, such as Amazon, Google, and Microsoft, need to increase their trustworthiness through enhancing cybersecurity, privacy, and sovereign data exchange. Smart infrastructure development and management could offer a compelling set of transformative use cases.

\section{Conclusions and Outlook}

Governments should promote the introduction of federated platforms for infrastructure planning and delivery and mandate multi-stakeholder and multidisciplinary teams to design and implement the most promising use cases to accelerate the transition towards Infrastructure 4.0. A federated digital platform approach enables the development of new ecosystems but without individual actors monopolizing them.

However, as already stressed above, technology and digitalization alone will not resolve the governance and strategic gap of the infrastructure industry. Thus, to complement the implementation of platforms, governments should establish National Infrastructure Councils to develop visions, realize long-term strategic planning, and develop and implement new participative models of infrastructure development. With the creation of national infrastructure councils, governments can make an extraordinary contribution to 
new and more vision-oriented, sustainable, and participatory planning and infrastructure delivery. They can provide and generate evidence-based proposals for action and act as a knowledge center and independent think tank, putting infrastructure development back at the center of societal attention. National infrastructure councils should govern local infrastructure councils, which are local/metropolitan agencies that plan, procure, and manage assets using the infrastructure platform model. In addition, a global network of national infrastructure councils and agencies could establish a fertile ecosystem of international experts bringing together global knowledge and research in this field.

A blueprint is already available with Infrastructure Victoria, which is an Australian infrastructure agency, developing infrastructure based on visions and public demand rather than on biased cost-benefit analysis, aiming to establish a stable institutional context that thinks beyond short-cycled politics [81,82]. Similar agencies or councils have recently been established in the UK and France [83].

As the basis for strategic discussions and decision-making concerning the future of infrastructure and the implementation of a learning platform, this paper does not propose specific technologies, but a holistic model of infrastructure development [21,84], as depicted above (Figure 7), helping to embark from linear waterfall models that have dominated infrastructure planning and delivery over decades.

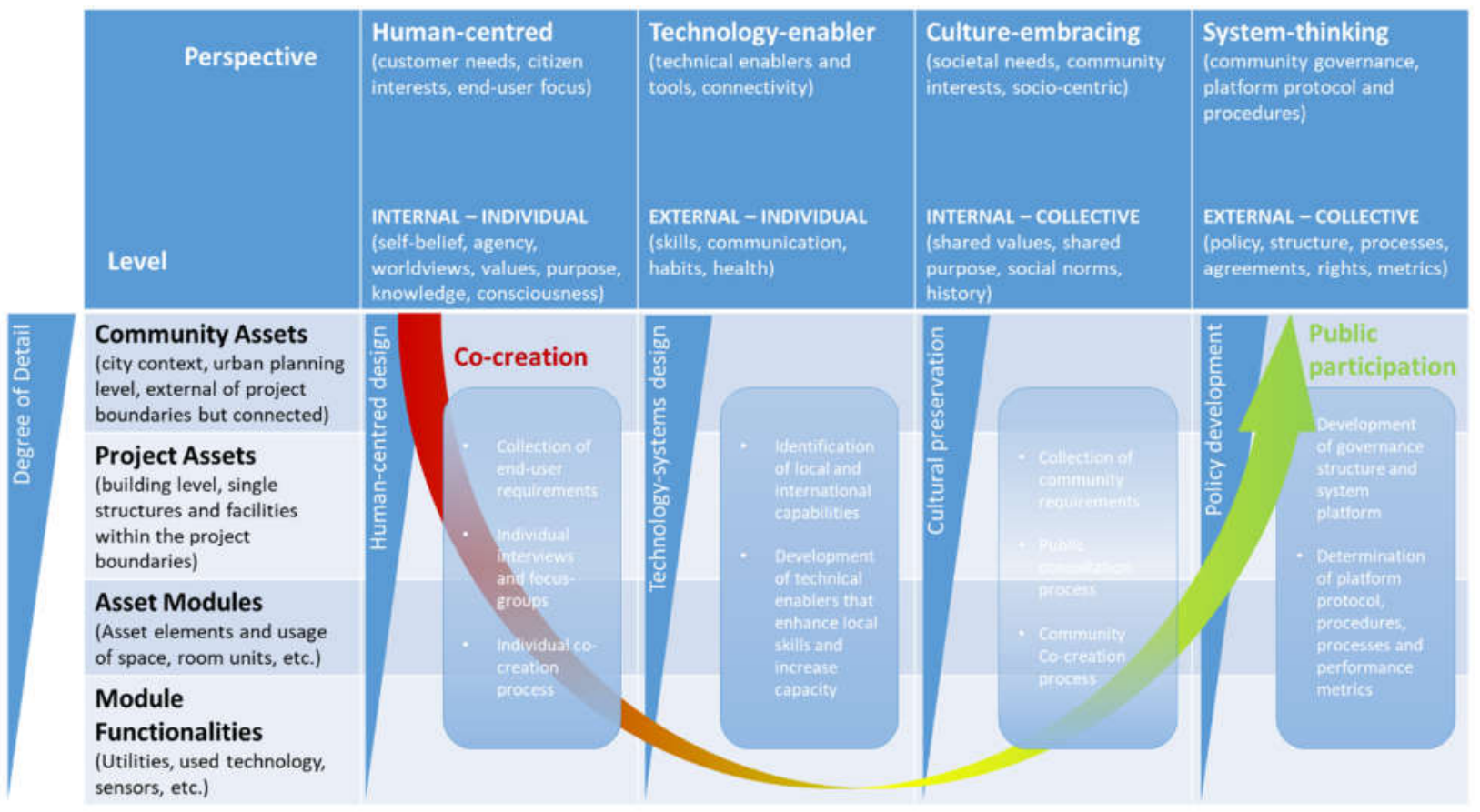

Figure 7. Holistic model of infrastructure development (in accordance to [21] and [84]).

Author Contributions: All three authors K.N., M.M.B. and T.J. contributed equably to this article. All authors have read and agreed to the published version of the manuscript.

Funding: This research received no external funding.

Institutional Review Board Statement: Not applicable.

Informed Consent Statement: Not applicable.

Acknowledgments: Content contributors as follows (in alphabetic order)-mainly by many teleconferences and an online workshop (25 March, organized by TUM-Leonhard-Obermeyer-Center, Konstanz University of Applied Sciences, Taihe Institute and the Association of construction companies, Bavaria: Norman Anderson, CG/LA Infrastructure; Glenn Ballard, UC Berkeley; Mark Bew, PCSG Limited; David Bowcott, Aon Risk Solutions; Kai Broek, Capgemini Invent; Gerd Buziek, Esri Deutschland $\mathrm{GmbH}$; Isabel Cane, OECD; Raffaele della Croce, OECD; Harry Dimitriou, University 
College London; Dale Evans, Project13; Volker Kefer, Verein Deutscher Ingenieure; Isidora Kosta, World Economic Forum; Thomas Maier, G20 Global Infrastructure Hub; Ibrahim Odeh, Columbia University; Rafael Sacks, Technion Israel Institute of Technology; Thomas Schmid, Bavarian Construction Industry Association; Hajnalka Vaagen, Norwegian University of Technology.

Conflicts of Interest: The authors declare no conflict of interest.

\section{Appendix A}

The article contributes as policy brief to the T20 "Task Force 7: Infrastructure Investment and Financing" and the policy areas "digital infrastructure", "infrastructure governance", and "technological advances" and builds upon the "G20 Principles for Quality Infrastructure Investment" by enhancing the "G20 InfraTech Agenda". The policy brief also contributes to the G20 Infrastructure Working Group (policy areas preparation and management) and supports the UN SDGs 9, 11, 13, and 17. This policy brief is based on research and numerous expert interviews carried out since July 2020. An international workshop to finalize the policy brief was held in Munich on 2 April 2021.

The policy brief addresses the following policy areas: exploiting technological advances for infrastructure development; strengthening infrastructure governance: openness, transparency and inclusion of local communities; new initiatives and mechanisms to support digital infrastructures; and integrating environmental criteria into infrastructure investment.

\section{References}

1. Munyasya, B.M.; Chileshe, N. Towards sustainable infrastructure development: Drivers, barriers, strategies, and coping mechanisms. Sustainability 2018, 10, 4341. [CrossRef]

2. Loorbach, D. Transition management for sustainable development: A prescriptive, complexity-based governance framework. Governance 2010, 23, 161-183. [CrossRef]

3. Vares, H.; Parvandi, Y.; Ghasemi, R.; Abdollahi, B. Transition from an efficiency-driven economy to innovation-driven: A secondary analysis of countries global competitiveness. Eur. J. Econ. Financ. Adm. Sci. 2011, 31, 124-132.

4. Tan, K.-S.; Phang, S.-Y. From Efficiency-Driven to Innovation-Driven Economic Growth: Perspectives from Singapore; World Bank Publications: Herndon, VA, USA, 2005; Volume 3569.

5. Schwab, R.; Zahidi, S.; World Economic Forum. The Global Competitiveness Report. Special Edition 2020: How Countries are Performing on the Road to Recovery; WEF: Geneva, Switzerland, 2020.

6. Rowley, A.H. Foundations of The Future: The Global Battle for Infrastructure; World Scientific: Toh Tuck Link, Singapore, 2020.

7. Ramamurti, R.; Doh, J.P. Rethinking foreign infrastructure investment in developing countries. J. World Bus. 2004, 39, 151-167. [CrossRef]

8. Cantarelli, C.C.; Flyvbjerg, B.; van Wee, B.; Molin, E.J.E. Cost overruns in large-scale transportation infrastructure projects: Which explanations can be given? In Proceedings of the 2008 First International Conference on Infrastructure Systems and Services: Building Networks for a Brighter Future (INFRA), Rotterdam, The Netherlands, 10-12 November 2008.

9. Flyvbjerg, B.N.; Bruzelius, N.; Rothengatter, W. Megaprojects and Risk: An Anatomy of Ambition; Cambridge University Press: Cambridge, UK, 2003.

10. Flyvbjerg, B.; Holm, M.K.S.; Buhl, S.L. What causes cost overrun in transport infrastructure projects? Transp. Rev. 2004, 24, 3-18. [CrossRef]

11. Flyvbjerg, B. Policy and Planning for Large-Infrastructure Projects: Problems, Causes, Cures. Environ. Plan. B Plan. Des. 2007, 34, 578-597. [CrossRef]

12. Tallberg, J.; Zürn, M. The legitimacy and legitimation of international organizations: Introduction and framework. Rev. Int. Organ. 2019, 14, 581-606. [CrossRef]

13. G20. About the G20, G20 website. 2021. Available online: https://www.g20.org/about-the-g20.html (accessed on 5 August 2021).

14. Ougaard, M. The transnational state and the infrastructure push. New Political Econ. 2018, 23, 128-144. [CrossRef]

15. GIHub. Forecasting Infrastructure Investement Needs and Gaps. G20 Global Infrastructure Outlook 2021. Available online: https:/ / outlook.gihub.org/ (accessed on 30 April 2021).

16. GIHub. Global Infrastructure Hub-A G20 Initiative. 2021. Available online: https://www.gihub.org/ (accessed on 2 August 2021).

17. OECD. OECD Infrastructure Working Group (IWG). 2021. Available online: https:/ / www.oecd.org/g20/topics/infrastructure/ (accessed on 2 August 2021).

18. WEF. WEF Infrastructure Initiatives. 2021. Available online: https://www.weforum.org/projects/infrastructure-4-0 (accessed on 2 August 2021). 
19. Bielenberg, A.; Kerlin, M.; Oppenheim, J.; Roberts, M. Financing Change: How to Mobilize Private-Sector Financing for Sustainable Infrastructure; McKinsey Center for Business and Environment: London, UK, 2016; pp. 24-25.

20. Cuttaree, V.; Mandri-Perrott, X.C. Public-Private Partnerships in Europe and Central Asia: Designing Crisis-Resilient Strategies and Bankable Projects; World Bank Publications: Herndon, VA, USA, 2011.

21. Wilber, K. Integral Politics: Its Essential Ingredients-Integral Life. 2018. Available online: https://integrallife.com/integralpolitics-its-essential-ingredients / (accessed on 2 August 2021).

22. World Bank. Infratech Value Drivers. 2020. Available online: https://openknowledge.worldbank.org/handle/10986/34320 (accessed on 2 August 2021).

23. World Bank. Infratech Policy Toolkit. 2020. Available online: https://openknowledge.worldbank.org/handle/10986/34326 (accessed on 2 August 2021).

24. G20 Infrastructure Working Group. G20 Riyadh InfraTech Agenda, G.I.W. 2020. Available online: https://cdn.gihub.org/umbraco/ media/3008/g20-riyadh-infratech-agenda.pdf (accessed on 2 August 2021).

25. Döringer, S. 'The problem-centred expert interview'. Combining qualitative interviewing approaches for investigating implicit expert knowledge. Int. J. Soc. Res. Methodol. 2020, 24, 265-278. [CrossRef]

26. Ochieng, E.; Price, A.; Moore, D. Major Infrastructure Projects: Planning for Delivery; Palgrave Macmillan: London, UK, 2017.

27. Department of Infrastructure and Transport. Infrastructure Planning and Delivery: Best Practice Case Studies; Department of Infrastructure and Transport: Canberra, Australia, 2012; Volume 2.

28. Narayanaswami, S. Urban transportation: Innovations in infrastructure planning and development. Int. J. Logist. Manag. 2017, 28, 150-171. [CrossRef]

29. Mell, I.; Allin, S.; Reimer, M.; Wilker, J. Strategic green infrastructure planning in Germany and the UK: A transnational evaluation of the evolution of urban greening policy and practice. Int. Plan. Stud. 2017, 22, 333-349. [CrossRef]

30. Wilker, J.; Rusche, K.; Rymsa-Fitschen, C. Improving participation in green infrastructure planning. Plan. Pr. Res. 2016, 31, 229-249. [CrossRef]

31. Hislop, M.; Scott, A.J.; Corbett, A. What does good green infrastructure planning policy look like? Developing and testing a policy assessment tool within Central Scotland UK. Plan. Theory Pract. 2019, 20, 633-655. [CrossRef]

32. Sinnett, D.; Smith, N.; Burgess, S. Handbook on Green Infrastructure: Planning, Design and Implementation; Edward Elgar Publishing: Cheltenham, UK, 2015.

33. Fellows, R.; Liu, A.M. Managing organizational interfaces in engineering construction projects: Addressing fragmentation and boundary issues across multiple interfaces. Constr. Manag. Econ. 2012, 30, 653-671. [CrossRef]

34. Benington, H.D. Production of large computer programs. Ann. Hist. Comput. 1983, 5, 350-361. [CrossRef]

35. Allee, V. The Future of Knowledge; Taylor \& Francis: Oxfordshire, UK, 2009.

36. Moser, H. Barriers to Bankable Infrastructure: Incentivizing Private Investment to Fill the Global Infrastructure Gap; Rowman \& Littlefield: Lanham, MD, USA, 2016.

37. Hein, A.; Schreieck, M.; Riasanow, T.; Setzke, D.S.; Wiesche, M.; Böhm, M.; Krcmar, H. Digital platform ecosystems. Electron. Mark. 2020, 30, 87-98. [CrossRef]

38. Samans, R.; Davis, N.; World Economic Forum. Advancing Human-Centred Economic Progress in the Fourth Industrial Revolution. A Leadership Agenda for G20 Governments; WEF: Geneva, Switzerland, 2017.

39. ElMassah, S.; Mohieldin, M. Digital transformation and localizing the Sustainable Development Goals (SDGs). Ecol. Econ. 2020, 169, 106490. [CrossRef]

40. Anumba, C.J.; Roofigari-Esfahan, N. Cyber-Physical Systems in the Built Environment; Springer: Manhattan, NY, USA, 2020.

41. Hetemi, E.; Ordieres-Meré, J.; Nuur, C. An Institutional Approach to Digitalization in Sustainability-Oriented Infrastructure Projects: The Limits of the Building Information Model. Sustainability 2020, 12, 3893. [CrossRef]

42. Hagel, J. The Power of Platforms: Part of the Business Trends Series; Deloitte University Press: Westlake, TX, USA, 2015.

43. Hagel, J.; Brown, J.S. From Push to Pull: Emerging Models for Mobilizing Resources. J. Serv. Sci. 2008, 1, 93-110. [CrossRef]

44. Hagel, J.; Brown, J.S. Shaping Strategies for the IoT. Computer 2017, 50, 64-68. [CrossRef]

45. Hagel, J. John Hagel's Personal Website. 2021. Available online: https://www.johnhagel.com/category/learning/ (accessed on 10 March 2021).

46. Passos, D.S.; Coelho, H.; Sarti, F.M. From Resilience to the Design of Antifragility. In Proceedings of the PESARO 2018: The Eighth International Conference on Performance, Safety and Robustness in Complex Systems and Applications, Athens, Greece, 22-26 April 2018.

47. Taleb, N.N. Antifragile: Things That Gain from Disorder; Random House Trade Paperback: New York, NY, USA, 2014; 519p.

48. Sawhney, A.; Riley, M.; Irizarry, J. Construction 4.0: An Innovation Platform for the Built Environment; Routledge: Abingdon, UK; New York, NY, USA, 2020.

49. Jelinek, T.; Wallach, W.; Kerimi, D. Policy brief: The creation of a G20 coordinating committee for the governance of artificial intelligence. AI Ethics 2020, 1, 141-150. [CrossRef]

50. Jelinek, T. The artificial intelligence governance gap. In Intelligent Decarbonisation: Can Artificial Intelligence and Cyber-Physical Systems Foster the Achievement of Climate Mitigation Targets; Inderwildi, O., Kraft, M., Eds.; Springer Nature: Cham, Switzerland, 2021.

51. OECD. Getting Infrastructure Right: The Ten Key Governance Challenges and Policy Options. The OECD Framework for the Governance of Infrastructure; OECD: Paris, France, 2017. 
52. WEF. Agile Regulation for the Fourth Industrial Revolution: A Toolkit for Regulators; World Economic Forum: Geneva, Switzerland, 2020

53. Kenny, C. Infrastructure Governance and Corruption: Where Next; World Bank Publications: Herndon, VA, USA, 2007 ; Volume 4331.

54. Anan, H.; Tang, J.; Maly, K.; Nelson, M.; Zubair, M.; Yang, Z. Challenges in building federation services over harvested metadata. In Proceedings of the International Conference on Asian Digital Libraries (ICADL), Kuala Lumpur, Malaysia, 8-12 December 2003.

55. Silva, J.d.C.; Rodrigues, J.J.P.C.; Al-Muhtadi, J.; Rabelo, R.A.L.; Furtado, V. Management platforms and protocols for internet of things: A survey. Sensors 2019, 19, 676. [CrossRef]

56. Fischer, M.; Ashcraft, H.; Reed, D.; Khanzode, A. Integrating Project Delivery; John Wiley \& Sons: Hoboken, NJ, USA, 2017.

57. Raj, P.; Raman, A.C. The Internet of Things: Enabling Technologies, Platforms, and Use Cases; CRC Press: Boca Raton, FL, USA, 2017.

58. Zhang, L.; He, J.; Zhou, S. Sharing tacit knowledge for integrated project team flexibility: Case study of integrated project delivery. J. Constr. Eng. Manag. 2013, 139, 795-804. [CrossRef]

59. West, M. The Approach to Develop the Foundation Data Model for the Information Management Framework. In National Digital Twin Programme; Centre for Digital Built Britain: Cambridge, UK, 2021.

60. Smith, P. BIM Implementation-Global Strategies. Procedia Eng. 2014, 85, 482-492. [CrossRef]

61. Kent, D.C.; Becerik-Gerber, B. Understanding construction industry experience and attitudes toward integrated project de-livery. J. Constr. Eng. Manag. 2010, 136, 815-825. [CrossRef]

62. Lloyd-Walker, B.M.; Mills, A.J.; Walker, D.H. Enabling construction innovation: The role of a no-blame culture as a collabo-ration behavioural driver in project alliances. Constr. Manag. Econ. 2014, 32, 229-245. [CrossRef]

63. Ostrom, E. Governing the Commons: The Evolution of Institutions for Collective Action; Cambridge University Press: Cambridge, UK, 1990.

64. Siddarth, D.E.G.W. The Case for the Digital Commons; World Economic Forum: Geneva, Switzerland, 2021.

65. Kroner, R.G.; Barbier, E.B.; Chassot, O.; Chaudhary, S.; Cordova, L.; Cruz-Trinidad, A.; Cumming, T.; Howard, J.; Said, C.K.; Kun, Z.; et al. COVID-era policies and economic recovery plans: Are governments building back better for protected and conserved areas? Park 2021, 27, 135-148. [CrossRef]

66. Bricout, J.; Baker, P.M.A.; Moon, N.W.; Sharma, B. Exploring the smart future of participation: Community, inclusivity, and people with disabilities. Int. J. E Plan. Res. 2021, 10, 94-108. [CrossRef]

67. Elkington, J. Enter the triple bottom line. In The Triple Bottom Line: Does It All Add Up; Henriques, A., Richardson, J., Eds.; Routledge: Oxfordshire, UK, 2004.

68. Mukhopadhyay, S.; Bouwman, H. Orchestration and governance in digital platform ecosystems: A literature review and trends. Digit. Policy Regul. Gov. 2019, 21, 329-351. [CrossRef]

69. Soto, J.C.; Kyt, W.; Jahn, M.; Pullmann, J.; Bonino, D.; Pastrone, C.; Spirito, M. Towards a Federation of Smart City Services. In Proceedings of the International Conference on Recent Advances in Computer Systems, Hail, Saudi Arabia, 30 November-1 December 2015.

70. World Economic Forum. Shaping the Future of Construction-Inspiring Innovators Redefine the Industry; WEF: Geneva, Switzerland, 2017.

71. Paruchuri, V.K. Adaptive Scalable Protocols for Heterogeneous Wireless Networks. Ph.D. Dissertation, Louisiana State University, Baton Rouge, LA, USA, August 2006.

72. Gritsenko, D.; Wood, M. Algorithmic governance: A modes of governance approach. Regul. Gov. 2020. [CrossRef]

73. Jelinek, T. The future rulers? On artificial intelligence ethics and governance. In Reset Europe: Time for Culture to Give Europe New Momentum; Billows, W., Körber, S., Eds.; Institut für Auslandsbeziehungen (IFA): Stuttgart, Germany, 2020; pp. $244-252$.

74. Howell, G.; Ballard, G.; Demirkesen, S. Why lean projects are safer. In Proceedings of the 25th Annual Conference of the International Group for Lean Construction, Heraklion, Greece, 9-12 July 2017.

75. Ballard, G. The lean project delivery system: An update. Lean Constr. J. 2008, 2008, 1-19.

76. Ballard, G.; Tommelein, I. 2020 Current Process Benchmark for the Last Planner (R) System of Project Planning and Control; Project Production Systems Laboratory: Berkley, CA, USA, 2021.

77. Klostermeier, R.; Haag, S.; Benlian, A. Geschäftsmodelle Digitaler Zwillinge: HMD Best Paper Award 2018; Springer: Wiesbaden, Germany, 2019.

78. Diran, D.; Van Veenstra, A.F.; Timan, T.; Testa, P.; Kirova, M. Artificial Intelligence in Smart Cities and Urban Mobility: How Can Artificial Intelligence Applications Be Used in Urban Mobility and Smart Cities and How Can Their Deployment Be Facilitated. Think Tank Briefing: Requested by the AIDA Committee; European Parliament IPOL: Strasbourg, France, 2021.

79. IDSA. International Data Spaces-The Future of the Data Economy Is Here. 2021. Available online: https:/ / internationaldataspaces. org/ (accessed on 2 August 2021).

80. Perset, K.; Muridik, D.; Clark, J.; Grobelnik, M. A First Look at the OECD's Framework for the Classification of AI Systems, Designed to Give Policymakers Clarity, in the AI Wonk, P. Observatory, Editor. 2020. Available online: https:/ / oecd.ai/wonk/afirst-look-at-the-oecds-framework-for-the-classification-of-ai-systems-for-policymakers (accessed on 2 August 2021).

81. Masson, M. Infrastructure Victoria. 2021. Available online: https://www.infrastructurevictoria.com.au/ (accessed on 10 March 2021).

82. Infrastructure Victoria. Victoria's Draft 30-Year Infrastructure Strategy; Infrastructure Victoria: Melbourne, Australia, 2016. 
83. Armitt, J. National Infrastructure Commission Website-_"Impartial, Expert Advice on Major Long Term Infrastructure Challenges". 2021. Available online: https:/ / nic.org.uk/ (accessed on 10 March 2021).

84. Scharmer, O. The Essentials of Theory U: Core Principles and Applications; Berrett-Koehler Publishers: Oakland, CA, USA, 2018. 